\title{
Verdieping en reflectie: kritiek in literaire tijdschriften
}

\author{
FLOOR VAN RENSSEN
}

In mijn onderzoek naar de Nederlandse literaire kritiek over Vlaamse literatuur in de periode 1980-1995 doorzoek ik de belangrijkste landelijke kranten en weekbladen, om in kaart te brengen wat er door Nederlandse critici wordt geschreven over Vlaamse literatuur, en hóe daarover wordt geschreven. Als onderdeel van een vNC-project wordt samengewerkt met de Katholieke Universiteit Leuven; de Vlaamse onderzoeker Ben van Humbeeck speurt de Vlaamse kranten en weekbladen na op recensies over Nederlandstalige literatuur. Doel van dit project is het in kaart brengen van de interactie op het gebied van de literatuur tussen Nederland en Vlaanderen in de periode 1980-1995. De literaire kritiek wordt hierbij opgevat als eerste graadmeter voor de literaire situatie, weliswaar in samenhang met andere instituties: de wereld van de uitgeverijen, literaire prijzen, et cetera. Langs deze weg willen we achterhalen in hoeverre de Vlaamse en de Nederlandse literatuur verweven zijn. Kunnen we spreken van één systeem van de Nederlandstalige literatuur, of beter van twee verschillende systemen?

Voordat het onderzoek van start ging rees de vraag of we ons onderzoek moesten beperken tot de recensies in dag- en weekbladen, of dat we ook de literaire tijdschriften erbij moesten betrekken. Voor mij leek het duidelijk dat de kritiek in literaire tijdschriften van heel andere aard is dan die in dagen weekbladen. De Vlaamse kant van het onderzoeksproject vond dit echter minder vanzelfsprekend. Hoewel dit verschil in opvatting waarschijnlijk vooral te maken heeft met de andersoortige literaire situatie in beide landen, zette mij dit wel aan het denken. Is er in Nederland daadwerkelijk een verschil tussen de tijdschriften en de dagbladpers, als het gaat om recensies van contemporaine literatuur?

In het artikel 'Ook dichteressen rijden auto. De toekomst van het literaire tijdschrift in Nederland en Vlaanderen' stelt Siem Bakker dat er een fundamenteel verschil is tussen de kritiek in kranten en tijdschriften. Hij verzet 
zich tegen de opvatting van enkele sceptische critici dat het literaire tijdschrift in het huidige tijdperk van multimedia zijn functie zou hebben verloren. Een van hen, Jaap Goedegebuure, verklaarde in 1994 dat het literaire tijdschrift 'niet meer van deze tijd' zou zijn. 'De dag- en weekbladpers, radio en televisie zouden hun kernfuncties hebben overgenomen.' ${ }^{\prime}$ Siem Bakker brengt hier tegenin dat de kernfuncties van het literaire tijdschrift simpelweg ánders zijn dan die van de literaire kritiek: 'Je mag veronderstellen dat ze [sceptische critici, FvR] de joumalistiek-recenserende en actueel opiniërende functies van de media scherp hadden kunnen onderscheiden van de essayistischkritische en afstandelijk reflectieve functies, die van oudsher zo eigen zijn aan het genre van het literaire tijdschrift.'

Hij maakt dus een onderscheid tussen twee typen kritiek: de recenserende pers in de kranten, en de kritische essayistiek in de tijdschriften. Recensies zoals die in de kranten verschijnen hebben nooit tot de kernfuncties van een literair tijdschrift behoord, maar ze komen wel voor. De recenserende pers en de kritische essayistiek raken en overlappen elkaar dan. De dag- en weekbladen hebben echter altijd een voorsprong, door de snelheid en frequentie van verschijnen, 'waardoor ze de eerste beoordeling van nieuw verschenen werk naar zich toe hebben getrokken. [...] Het type recensie dat nu nog in enkele tijdschriften verschijnt, kan beter worden omschreven als retrospectief, zowel om de tijdsafstand als om de daarin verwerkte reflectie op de eerste, journalistieke receptie-stroom,' aldus Bakker. ${ }^{2}$ Er wordt in literaire tijdschriften vaak commentaar geleverd op de kritiek zoals die in de dagbladen bedreven wordt, en er wordt vaak dieper ingegaan op de aard en het belang van literaire werken. De kritiek in tijdschriften zou dus specialistischer zijn dan die in de dag- en weekbladen.

Het verschil tussen Vlaanderen en Nederland zou zijn dat dit onderscheid tussen soorten kritiek in dagbladen en tijdschriften voor Vlaanderen niet zo duidelijk is te maken. Het Vlaamse literaire circuit beschikt eenvoudig niet over zulke uitgebreide geïnstitutionaliseerde boekenbijlagen als het Nederlandse, is de veronderstelling. Deze kwestie verdient zeker verder onderzoek, maar het lijkt erop dat er in de Vlaamse dagbladen pas sinds eind jaren tachtig sprake is van consequente aandacht voor de actuele literaire productie. Het gaat dan om De Standaard, met de bijlage 'Standaard der Letteren', 
waarin critici wekelijks recent verschenen boeken bespreken, en De Morgen, die sinds eind jaren tachtig over een wekelijkse boekenbijlage beschikt. Helaas ontbreken op dit moment nog betrouwbate cijfers op dit gebied. Een van de doelstellingen van het vNC-project is dan ook juist in deze leemte te voorzien. Onderzoeker Ben van Humbeeck ( $\mathrm{KU}$ Leuven) zal aan het eind van het project antwoord kunnen geven op de vraag hoe de literaire kritiek in Vlaanderen zich in de jaren tachtig ontwikkeld heeft, en wat de reden zou kunnen zijn voor het feit dat de ontwikkeling van de Vlaamse dagbladkritiek later op gang is gekomen dan die in Nederland.

Omdat de literaire dagbladkritiek in Vlaanderen niet omvangrijk was, aldus de hypothese, zou de 'recenserende pers' zich ook uitstrekken over de literaire tijdschriften, waarin bovendien vaak dezelfde critici schreven. De 'primaire' literaire kritiek zou zich dus ook in de tijdschriften afspelen, omdat de dagbladen niet volledig zouden voorzien in de behoefte aan een kritische selectie uit het actuele aanbod. Volgens deze hypothese vervullen de dagbladkritiek en de kritiek in litetaire tijdschriften in Vlaanderen dus geen onderscheiden functie. Dan zou het niet verantwoord zijn in een onderzoek naar de Vlaamse literaire kritiek de literaire tijdschriften buiten beschouwing te laten; het zou een onvolledig en vertekend beeld opleveren. Maar voor Nederland ligt dat dus anders, als we afgaan op het artikel van Siem Bakker.

Over de ontwikkeling van de literaire kritiek in Nederland zijn meer gegevens voorhanden dan over de Vlaamse situatie. De Nederlandse dagbladkritiek heeft sinds de jaren zeventig een sterke groei doorgemaakt. Als gevolg van sociaal-economische ontwikkelingen ontstond een groter publiek voor (kwaliteits-)kranten, en steeg het aantal advertentiepagina's. Dit ging gepaard met een stijging van het aantal redactionele pagina's die werden gevuld met artikelen over kunst, amusement, wetenschap, mode, gezondheid et cetera. Zo ontstonden regelmatig terugkerende rubrieken en bijlagen en kregen onder andere de boekrecensies een vaste plek. ${ }^{3}$ Er werd meer aandacht geschonken aan verschillende kunstvormen, maar vooral de literatuur profiteerde van de toename in ruimte. Tussen 1965 en 1990 is het aantal pagina's gewijd aan literatuur bijna verdrievoudigd en in de kwaliteitskranten is van alle kunstvormen de aandacht voor literatuur het sterkst toege- 
nomen. ${ }^{4}$ Deze groei heeft ook geleid tot verdere professionalisering van de dagbladkritiek, in die zin dat er meer critici en redacteuren in vast dienstverband voor een krant schrijven, en dat de kunst- en cultuurredacties een relatief zelfstandige positie hebben verworven binnen de redacties van de kranten. In de jaren negentig hebben we te maken met een vrij uitgebreide en goed geïnstitutionaliseerde literatuurkritiek in Nederland.

Maar welke ontwikkeling heeft zich gelijktijdig voorgedaan in de literaire tijdschriften? Hoe hangt de kritiek in tijdschriften samen met de kritiek in dag- en weekbladen? Zijn de verschillen tussen 'recenserende pers' en 'kritische essayistiek' ook daadwerkelijk waar te nemen? De vraag die ik uiteindelijk wil beantwoorden, is of de literaire tijdschriften mede van belang kunnen zijn voor mijn onderzoek naar literaire kritiek.

Om dit te achterhalen heb ik de Nederlandse literaire tijdschriften zelf onder de loep genomen. Ik had daarbij een voortreffelijk hulpmiddel tot mijn beschikking: De bibliografie van literaire tijdschriften in Vlaanderen en Nederland, samengesteld door Hilda van Assche (Antwerpen: Rob Roemans-Stichting, 1974-2001 [verschijnt eenmaal per jaar tot 2000; voortgezet als 'online resource']). In deze bibliografie staat van elk tijdschrift per jaar de inhoud vermeld, onderverdeeld naar type tekst: 'proza', 'poëzie' en 'kritische bijdragen'. Ondet die laatste categorie vallen alle teksten die niet tot de twee andere categorieën behoren, zoals essays, inleidingen, recensies en interviews. Dankzij een korte omschrijving van de inhoud van de artikelen is vrij snel vast te stellen wat voor soort kritische artikelen er in de tijdschriften werden gepubliceerd.

Om de landelijke literaire dagbladkritiek te kunnen vergelijken met de literaire tijdschriften beperkte ik me tot de landelijke tijdschriften, dat wil zeggen de tijdschriften die zich in de eerste plaats op de landelijke literaire productie richten en een landelijk publiek bereiken (hoe klein dit publiek ook mag zijn). Regionaal georiënteerde tijdschriften en tijdschriften met een duidelijk levensbeschouwelijke achtergrond of een tijdschrift als het feministische Chysallis, liet ik dus buiten beschouwing. Als belangrijk nevencriterium heb ik aangehouden dat de tijdschriften gedurende de hele periode van onderzoek (1980-1995) consequent verschenen, om zo de ontwikkeling van de literaire kritiek vast te kunnen stellen. 
Het resultaat was een lijst van acht tijdschriften. Daarvan vielen et drie meteen af op grond van het type. Bzzlletin bijvoorbeeld is een geval apart: elk nummer is een soort 'schrijversprentenboek' in de vorm van een magazine. De Tweede Ronde en Raster plaatsten nauwelijks artikelen over literatuut, maar concentreerden zich op primaire bijdragen: proza en poëzie van nieuw talent. Deze tijdschriften komen dus niet in aanmerking voor onderzoek van de ontwikkeling in de literaire kritiek. Een uitgebreide verkenning van De Revisor liet zien, dat ook dit tijdschrift nauwelijks ruimte bood aan kritiek. Er is wel plaats voor theoretische essays, maar recensies heb ik er niet gevonden. Wat betreft De Revisor kan dus vastgesteld worden dat de hypothese klopt: er is vooral ruimte voor reflectie en retrospectie, niet voor 'recenserende kritiek'. Over twee tijdschriften heb ik getwijfeld. In 1981 verscheen New Found Land dat al na twee jaargangen samenging met De Revisor en om die reden buiten beschouwing is gelaten. Verder heb ik het tijdschrift Optima, opgericht in 1983, doorgenomen maar ook daarin was geen literaire kritiek te vinden.

De vier overgebleven tijdschriften voldoen in grote lijnen aan het beeld van het 'typische literaire tijdschrift', zoals Bakker dat omschrijft: ze geven een combinatie van nieuw primair werk, zowel van gevestigde als beginnende schrijvers en dichters, van literair-historische en theoretische artikelen en van de kritische begeleiding van de contemporaine literaire productie. ${ }^{5}$ Dat zijn Maatstaf, Hollands Maandblad, De Gids en Tirade.

Het onderhavige onderzoek van deze beredeneerde selectie van vier tijdschriften is in de vorm van een steekproef uitgevoerd. Elk van de tijdschriften is steekproefsgewijs onderzocht. Om zo goed mogelijk een beeld van de ontwikkeling van de literaire kritiek te kunnen schetsen, heb ik me laten leiden door de aanpak van literatuursocioloog Rosengren zoals beschreven door Gaiser. Rosengren onderzocht de canon van de Zweedse dagbladkritiek: door verschillende perioden van enkele dicht bij elkaar gelegen jaren te onderzoeken en met elkaar te vergelijken, kon hij een beeld schetsen van de wijze waarop de literaire situatie veranderd is. ${ }^{6} \mathrm{Ik}$ heb drie perioden gekozen en onderling vergeleken. De eerste periode bestaat uit de jaren 1980-1982, periode twee uit de jaren 1985-1987 en periode drie uit de jaren 1990-1992. 
De resultaten

Tijdens het onderzoek viel mij op hoeveel aandacht er is voor niet-literaire onderwerpen. Met name in Hollands Maandblad en De Gids is veel ruimte voor essays over allerlei sociaal-culturele, politieke en historische onderwerpen. Hollands Maandblad draagt niet voor niets de ondertitel 'tijdschrift voor literatuur en politiek', en De Gids, ooit berucht als 'de blauwe beul', heeft zich sinds de redactiewisseling van 1965 ontwikkeld tot een 'algemeen cultureel maandblad'. Dit blijft zo tot in de jaren negentig. ${ }^{7}$ In mijn onderzoeksperiode vind ik bijvoorbeeld essays over het kernwapendebar, energieschaarste, werkloosheid, de kraakbeweging, seksuele hervorming... Literaire tijdschriften lijken dus niet alleen voor literatuurhistorici interessant. Maatstaf en Tirade richten zich minder sterk op algemeen maatschappelijke kwesties. In deze tijdschriften komen buiten de literaire onderwerpen vooral beeldende kunst, fotografie en kunstbeleid aan bod.

Terug naar de kritiek. Ik trof relatief weinig echte recensies aan. Onder een echte recensie versta ik: een bespreking van enige omvang van een net verschenen boek, die informatie geeft over het werk (zoals over inhoud, stijl, auteur) én een literair waardeoordeel velt. De Gids verzorgt gedurende alle jaren van mijn onderzoek de rubriek 'Kroniek en kritiek' waarin teksten zijn opgenomen over actuele onderwerpen, zoals boven genoemd. In $1981 \mathrm{ko-}$ men daarin voor het eerst literaire kritieken voor, van Aleid Truijens. In periode twee van mijn onderzoek (1985-1987) schrijven Remco Ekkers en Wiel Kusters in deze rubriek over poëzie. Ekkers schrijft echte recensies, Kusters over alles wat met poëzie te maken heeft. Vanaf 1981 vinden we ook in Maatstaf regelmatig terugkerende kritiek: in elk nummer verschijnt de rubriek 'Ceterum censeo' waarin Rob Schouten steeds drie of vier net verschenen poëziebundels bespreekt. Deze rubriek verdwijnt langzaam in de tweede periode, maar in periode drie keert Schouten terug met regelmatige poëziebesprekingen. Terwijl de kritiek in Maatstaf iets terugloopt komt Tirade met een nieuwe kritische rubriek: Tomas Lieske bespreekt vanaf de tweede periode uitgebreid een net verschenen poëziebundel. Behalve deze rubrieken komen we hier en daar een uitgebreide kritische bespreking tegen, onder meer van Herman de Coninck in Tirade. Meestal zijn dit essayistische besprekingen met veel aandacht voor analyse van het werk. Vaak komt daarbij ook de receptie in de dagbladkritiek ter sprake. 
Daarnaast is met name in de jaren $1980-1982$ in Tirade de weetslag te vinden van een poëticaal debat: Jaap Goedegebuure bespreekt de kritische praktijk van verschillende recensenten: Carel Peeters, Aad Nuis, K.L. Poll, Tom van Deel, Wam de Moor. Hij levert commentaar op hun manier van recenseren en bespreekt de machtsstrijd die zij onderling uitvechten. De polemische stukken van Jeroen Brouwers en Jaap Goedegebuure werpen een interessant licht op de literaire kwesties die toen speelden. In alle onderzochte jaren kwam ik essays tegen over de normen en maatstaven van de literaire kritiek, hoewel ze zich concentreerden in de eerste periode. ${ }^{8}$ Deze artikelen leveren een schat aan informatie, juist omdat ze relatief snel reageren op actuele ontwikkelingen, terwijl er naar verhouding veel ruimte is voor reflectie.

De resultaten van onderzoek bevestigen het beeld dat Siem Bakker schetst in Ons Erfdeel. De literaire kritiek was in het begin van de jaren tachtig al niet prominent aanwezig, tien jaar later neemt ze nog steeds een bescheiden plaats in. Recensies behoren in alle drie de onderzochte perioden inderdaad niet tot de kernfuncties van de tijdschriften.

Maar er zijn wel verschillen tussen de perioden te zien. In de recensies die in de jaren negentig verschijnen lijkt de nadruk meer op analyse en retrospectie te liggen en minder op het oordeel. Het type oordelende recensie uit de eerste periode, met name van Rob Schouten, heeft plaats gemaakt voor essayistische besprekingen.

Daarnaast valt op, dat er in de eerste periode het felst wordt gedebatteerd over aard en functie van de (dagblad)kritiek. Het gaat er levendig aan toe. Er wordt veel geschreven over de positie van specifieke critici en er wordt commentaar geleverd op hun praktijk van recenseren. Toenmalig Tirade-redacteur Goedegebuure geeft in 1980 een mogelijke verklaring voor de onderlinge strijd tussen critici: de kritiek in dag- en weekbladen groeide snel en in deze ontwikkeling wilden de verschillende critici allemaal een vooraanstaande positie bevechten:

De kritikus is zich gaan manifesteren als een factor waarmee rekening gehouden moet worden; daarom vindt hij het van groot belang opinies over recent verschenen literatuur zo snel mogelijk, het liefst vóórdat de collega's ook zo ver zijn, in de krant te hebben. ${ }^{9}$ 
Het zou kunnen dat die situatie in periode drie, 1990-1992, is gestabiliseerd, als de groei van de kritiek is gestuit en de vooraanstaande posities zijn verdeeld.

Een andere verandering zou hiermee te maken kunnen hebben: het lijkt erop dat er in periode drie minder wordt gereageerd op de actuele literaire situatie. Er verschijnen veel essays over historische onderwerpen en oudere literatuur; ook worden er opvallend veel gelegenheidsteksten afgedrukt, bijvoorbeeld lezingen, teksten dus die niet speciaal voor de tijdschriften werden geschreven. Al deze aspecten samen geven een beeld van relatieve stilte in vergelijking met tien jaar eerder.

Er zijn dus inderdaad grote verschillen tussen de kritiek in de tijdschriften en in de kranten. Ik zal die verschillen laten zien aan de hand van enkele voorbeelden en vervolgens nagaan wat dit betekent voor mijn onderzoek.

Twee typen kritiek

De voorbeelden die de verschillen in typen kritiek het best illustreren, komen uit de eerste periode, de jaren 1980 tot 1982 . Ook in dit opzicht lijkt het de periode waarin er het meest aan de hand is: de levendigste voorbeelden zijn daar te vinden.

In 1981 vraagt Aleid Truijens zich af in De Gids welke twee romans haar het meest zijn bijgebleven van al het literair proza dat de afgelopen tijd verscheen. $Z e$ is zich bewust van haar taak als criticus van een literair tijdschrift en vraagt zich af hoe ze die taak moet vervullen tegenover de dagbladkritiek:

Wat stond mij nog te doen? Ik vond dat het geen zin had mijn commentaar op al dat proza nog eens te laten horen nadat critici als Nuis, Kruithof en De Rover dit al zo vakkundig hadden gedaan. Ik heb daarom gekozen voor twee boeken die mij dit jaar troffen door hun overrompelende kwaliteit en die voor mij ten opzichte van al het andere proza op een eenzame hoogvlakte verkeren. ${ }^{10}$

Deze twee boeken zijn Ritulen van Cees Nooteboom en zijn novelle Een lied van schijn en wezen, kort na elkaar verschenen. Truijens bespreekt de receptie van deze boeken in de dagbladen, waarna ze de boeken zelf uitvoerig analyseert en bespreekt. Alleen al in de lengte van de bespreking wijkt deze 'recensie' af van die in de dag-en weekbladen, waar nooit veel ruimte is voor 
een kritiek. Verder verschijnt deze bespreking langer na de verschijningsdatum van deze twee boeken, waardoor Truijens de eerdere receptie in de dagbladkritiek in haar stuk kan betrekken.

Uit het citaat blijkt dat zij er weinig voor voelt het werk van de dagbladcritici over te doen, zij doen dat al goed genoeg. Ze kiest voor een diepgravender vorm van kritiek: ze maakt de balans op van alles wat door de dagbladkritiek is besproken. Als 'essayistisch' criticus van De Gids borduurt ze voort op de selectie die al door de literaire kritiek is gemaakt.

We herkennen hier de twee typen kritiek die Bakker noemde. Beide vormen gaan op een eigen manier te werk en hebben een andere functie. Deze verschillende functies zijn eerder beschreven door Susanne Janssen in haar proefschrift over literaire kritiek en auteurscarrières. Kwantitatief onderzoek heeft uitgewezen dat de journalistieke criticus vooral de rol van gatekeeper vervult: deze maakt een eerste selectie uit het aanbod. Daarmee vormt de dagbladkritick de eerste fase in het proces van canonisering. De essayistische en academische critici werken die eerste keuzes verder uit: zij bepalen wat de moeite waard is voor vervolgstudies en voortgezet onderzoek. Via essays in de literaire tijdschriften worden literaire werken onderwerp van wetenschappelijke publicaties. Zo wordt uireindelijk bepaald wat er in de literatuurgeschiedenis belandt en welke literatuur voor het nageslacht behouden blijft.

De rol van de dagbladkritiek is dus cruciaal in het canoniseringsproces. Uit empirisch onderzoek is gebleken, dat de aandacht van essayisten en academische literatuurbeschouwers vooral uitgaat naar het werk van auteurs die in de journalistieke kritiek een prominente rol hebben gespeeld. Boeken die als waardevol en belangrijk worden erkend door academici, werden bij verschijnen bijna altijd positief gewaardeerd door de dagbladkritiek. 'De activiteiten binnen de onderscheiden segmenten van de kritiek hebben dus een complementair karakter,' aldus Janssen, 'teksten moeten eerst de selectie van de journalistieke kritiek doorstaan om vervolgens eventueel onderwerp van bespreking te worden in kringen van essayisten en academici.' Volgens Janssen participeren de verschillende categorieën critici in één en hetzelfde proces, dat resulteert in cen afbakening en hiërarchisering van het literaire repertoire.' ${ }^{11}$ De verschillende critici vormen dus samen de institutie lite- 
raire kritiek, maar hebben daarbinnen elk een eigen taak die kortweg omschreven kan worden als verdieping tegenover selectie: verdieping in de tijdschriften tegenover eerste selectie in de dagbladen.

Door alle drie de perioden herken ik die onderscheiden functies. In retrospectieve beschouwingen, bijvoorbeeld in themanummers, wordt de balans opgemaakt van wat er is verschenen, wat veel aandacht van de dagbladcritici ontving en of dat ook terecht was. Een voorbeeld uit de derde periode is het Maatstaf-artikel van Arnold Heumakers en Willem Kuipers, 'Goden en mindere goden' waarin zij Van der Heijden, Kellendonk en Oek de Jong beschouwen als de belangrijkste jonge schrijvers en misschien wel opvolgers van 'de grote drie'. ${ }^{2}$

Dit voorbeeld illustreert tevens een ander aspect. In de opvatting van Janssen werken essayistische en academische kritiek samen, waarbij de academische kritiek voortborduurt op de keuzen van de literaire tijdschriften. Op het artikel van Heumakers en Kuipers kwam een reactie uit de hoek van de academische literatuurbeschouwing: de Utrechtse neerlandici Frans Ruiter en Wilbert Smulders reageerden eerst in Maatstaf en verwerkten hun reactic later in hun boek Literatuur en moderniteit in Nederland 1840-1990 uit 1996.13 De discussie over de opvolging van 'de grote drie', een echte canondiscussie, werd geïnitieerd door dagbladcritici en is via de tijdschriften in de academische literatuurbeschouwing beland.

Vanaf nummer twee van de negenentwintigste jaargang schrijft Rob Schouten in Maatstaf echte recensies: volgens Schouten is het de bedoeling de lopende poëtische productie in Nederland zo veel en compleet mogelijk bij te houden'. Dat is 'eigenlijk' de taak van de dagbladkritiek, maar deze functie wordt door de journalistieke kritiek steeds minder vaak vervuld:

Er wordt tegenwoordig aantoonbaar minder plaats in dag- en weekbladen ingeruimd voor poëziekritiek dan bijvoorbeeld voor de tweede wereldoorlog, toen een beetje dichter al gauw op een vier koloms recensie kon rekenen. [...] Het komt er in feite op neer dat slechts een klein topje van de berg dichters die ons land en onze tijd, ondanks de culturele inflatie, nog steeds rijk is, de attentie krijgt waarop ze recht heeft. [...] Elke ware dichter, vergeten of geëerd, of hij mij bevalt of niet, krijgt 
mooi dezelfde ruimte zodat niemand over zevenhonderd jaar, als de Nederlandse poëzie zal bestaan uit zeven regels van zeven verschillende dichters, dit schamele resultaat aan de voorselectie door tijdgenoten van de bevlogenen kan wijden. ${ }^{14}$

Net als Aleid Truijens is Rob Schouten zich bewust van zijn positie ten opzichte van de dagbladkritiek. De kritiek in tijdschriften fungeert als aanvulling op de dagbladkritiek, in dit geval omdat de kritiek met betrekking tot poëzie vrijwel ontbreekt. Daarnaast is Schouten zich bewust van de verantwoordelijkheid van de criticus; de voorselectie van critici bepaalt in hoge mate wat bewaard blijft voor het nageslacht, aldus de stelling in de laatste regels van dit citaat. Zijn recensies lijken op recensies in dag- en weekbladen, maar hij koppelt ze aan beschouwingen over de stand van zaken in de poëzie.

Naar aanleiding van deze voorbeelden zou ik de volgende hypothese willen opstellen. Het lijkt erop dat zolang de dagbladkritiek haar werk goed doet, de functies van de verschillende categorieën kritiek gescheiden blijven. Als de dagbladkritiek het literaire aanbod onvoldoende bespreekt neemt de kritiek in tijdschriften de rol van gatekeeping over. Deze redenering lijkt overeen te stemmen met de veronderstelde situatie in Vlaanderen: de tijdschriften nemen de rol van selectie op zich, die in de kranten ontbreekt. Ik ben benieuwd of het onderzoek van mijn Vlaamse collega deze hypothese zal kunnen bevestigen.

Er is dus een duidelijk verschil tussen beide typen kritiek, maar ze functioneren wel in relatie tot elkaar. De dagbladkritiek neemt een primaire plaats in, de tijdschriftkritiek lijkt zich daarnaar te voegen: waar nodig vult ze aan, overigens werkt ze de primaire selectie verder uit in de zin van verdieping en reflectie. Het verschil in de afstand in tijd zorgt ervoor dat de verschillende functies in principe behouden blijven. In tijdschriften is meer ruimte voor reflectie dan in de dagbladen. Dagbladen kunnen sneller reageren en selecteren, omdat ze frequenter verschijnen.

Het belang van tijdschriftenonderzoek

Enerzijds rechtvaardigt deze conclusie de keuze om in eerste instantie alleen 
de kritiek in dag- en weekbladen te onderzoeken: de keuzes van de dagbladkritiek zijn van primair belang, de dagbladkritiek heeft een heel eigen vorm en kan op haar eigen specifieke functie worden onderzocht. Anderzijds zijn beide typen kritiek zo nauw met elkaar verbonden, dat je de één wellicht niet los van de ander kunt zien: ze participeren 'in één en hetzelfde proces van afbakening en hiërarchisering', om Susanne Janssen aan te halen. Het onderzoek naar tijdschriften kan dus een belangrijke aanvulling zijn op het onderzoek naar journalistieke kritiek.

Een bekend probleem van de dagbladkritiek is namelijk dat de maatstaven die worden gehanteerd meestal niet geëxpliciteerd worden, terwijl het juist de onderliggende kwaliteitscriteria zijn die voor mij als onderzoeker interessant zijn. Of het met ruimtegebrek te maken heeft of met een gewoonte van critici om persoonlijke poëticale opvattingen als algemeen geldend voor te stellen, er wordt vaak weinig ruimte genomen voor het expliciteren van die opvatringen. De achtergrondinformatie uit de tijdschriften kan helpen dit probleem te ondervangen, mede omdat niet zelden dezelfde critici die in de dagbladen schrijven, ook schrijven voor literaire tijdschriften, maar dan meer ruimte krijgen om hun standpunten toe te lichten.

Ik trof bijvoorbeeld veel beschouwingen aan over de verhouding van de Nederlandse tot de Vlaamse literatuur: in de jaren 1980-1982 werd er niet al te positief over de Vlaamse poëzie gedacht. 'Wat kan er voor goeds uit Vlaanderen komen, denkt niet alleen de karikaturale Nederlander, maar vooral ook de literatuurcriticus,' zegt Rob Schouten. ${ }^{15}$ Deze uitspraak lijkt symptomatisch: er lijkt consensus over te bestaan dat er uit Vlaanderen heel veel en heel slechte poëzie komt. In meerdere artikelen vind ik die opvatting terug. Maar in deze tijdschriftartikelen wordt ook stil gestaan bij mogelijke oorzaken daarvan en dat is iets wat in recensies meestal niet gebeurt. Het onderzoek naar tijdschriften geeft mij zo belangrijke informatie die het beeld dat onstaat uit dag- en weekbladen, kan completeren.

Ik wil de literaire tijdschriften dus graag in mijn onderzoek betrekken. Het is mij duidelijk geworden dat tijdschriften op alle mogelijke manieren een levendige, kritische blik op de actuele literaire situatie bieden, die ze in samenspel met de dagbladkritiek mede vormgeven. Artikelen in tijdschriften geven verdieping en achtergrond bij de journalistieke kritiek, en die achter- 
grond is voot historisch-documentair teceptie-onderzoek van groot belang. Wie zich in literaire tijdschriften verdiept, maakt de literatuurgeschiedenis van dichtbij mee; je ziet haar onder je handen ontstaan.

. FLOOR VAN RENSSEN (1979) werkt sinds begin 2005 aan de RU Nijmegen aan een onderzoek naar de interactie tussen de Nederlandse en Vlaamse literatuur, zoals die zichtbaar wordt in de literaire kritiek. Daarnaast is ze eindredacteur van literair tijdschrift Parmentier.

I Siem Bakker, 'Ook dichteressen rijden auto. De toekomst van het literaire tijdschrift in Nederland en Vlaanderen', in: Ons Erfdeel 45 (2002) 2 (maart-april), 241-25i, m.n. 242.

2 Bakker, 'Ook dichteressen', 243-245. 3 Susanne Janssen, 'Art journalism and cultural change: the coverage of the arts in Dutch newspapers 1965-1990', in: Poetios 26 (1999), 329-348, m.n. 335.

4 Janssen, 'Art journalism', 336 e.v. 5 Siem Bakker, Literaire tijdschriften van 1885 tot heden, Amsterdam 1985, 245.

6 G. Gaiser, 'Zur Empirisierung des Konansbegriff', in: Spiel, 2 (1983), 123-135.

7 Siem Bakker, Literaire tijdschriften, 25-36.

8 Zoals het artikel 'Het eeuwige weerwoord. Het waarde-oordeel in de literaire kritiek' van K.L. Poll in Hollands Maandblad Xxi11 (1981), 403-404. 9 Jaap Goedegebuure, 'De angst voor het leiderschap', in: Tirade (1980) 253, 131-136, m.n. 131-132. 1o Aleid Truijens, 'De tijd van Cees Nooteboom', in: De Gids 144 (1981) 6, 404-413. 11 Susanne Janssen, In het licht van de kritiek. Variaties en patronen in de aandacht van de literatuurkritiek voor auteurs en hun werken, Hilversum 1994, 23. 12 Arnold Heumakers en Willem Kuipers, 'Goden en mindere goden', in: Maatstaf 39 (1991) 8-9, 2-12.

13 Frans Ruiter en Wilbert Smulders, "Demoblisatie van de moderne schrijvers. Waarom de naoorlogse "grote drie" niet opgevolgd zullen worden', in: Maatstaf 40 (1992) 4, 1-26 en Frans Ruiter en Wilbert Smulders, Literatuur en modemiteit in Nederland 1840-1990. Amsterdam 1996, 260.

${ }_{14}$ Rob Schouten, 'Ceterum censeo', in: Maatstaf 29 (1981) 2, 81-86.

15 Rob Schouten, 'Ceterum censeo', in: Maatstaf 30 (1982) 2, 94-101, m.n. 94 